\title{
Hacia una nueva concepción de la responsabilidad social
}

\section{Towards a New Conception of the Social Responsibility}

Luis Felipe Solano Santos. Universidad Complutense de Madrid

Recibido 07-II-2009 - Aceptado 18-VI-2009

Resumen:

¿Cuál es el fundamento de la responsabilidad social corporativa en la actualidad? ¿Se trata acaso de una especie de moda pasajera o, por el contrario, responde a una necesidad derivada de una revolución social fatal e inexorable? Este artículo pone de manifiesto que la práctica de las Relaciones Públicas ha acabado por erradicar toda inquietud independiente de los factores pragmáticos en que se mueve la comunicación social. Además, pretende determinar la relación existente entre la "imagen pública" de una institución y el modo de asunción de la responsabilidad social que manifiesta con su conducta dicha institución.

Palabras clave:

Relaciones Públicas, responsabilidad social corporativa, imagen pública

Abstract:

What is the foundation of corporate responsibility at this moment? Is it a kind of fad or, rather, does it respond to a need arising an inexorable social revolution? This article claims that the practice of Public Relations has come to remove any independent concern of the pragmatic factors in the area of social communications. In addition, it tries to determinate the relationship between the public image of an institution and the mode of acceptance of social responsibility that such an institution offers to the public.

Key Words:

Public Relations, Corporate Social Responsibility, Public Image 


\section{Introducción}

La inmensa mayoría de las instituciones sociales, es decir, los entes colectivos formales, entre los que figuran el estado, la empresa económica, los partidos políticos y en última instancia, las instituciones más importantes de nuestro sistema sociopolítico, o sea, aquellos factores sobre los que reposa la civilización, surgen o parecen surgir como categorías históricas, es decir, elementos o ingredientes susceptibles de asegurar, en el momento exacto, el desenvolvimiento de la sociedad humana y su progresión "ad infinitum".

La carencia de una fundamentación rigurosa, abstracción hecha de factores meramente circunstanciales, ha determinado que haya habido que esperar cerca de un siglo para que el mundo empresarial adquiera conciencia de su responsabilidad tras haber asistido a una evolución histórica marcada por acontecimientos concretos como fueron las primeras acciones de Relaciones Públicas allá en el siglo XVIII, y su posterior cristalización en el siglo XIX, así como la adquisición de una conciencia social de lo que inicialmente se identifica como filantropía y, más tarde, como responsabilidad social. Es necesario identificar en qué se manifiesta la asunción de dicha responsabilidad, responsabilidad que cristaliza en lo que ha dado en llamarse "imagen” publica de una institución o "reputación” social.

El presente trabajo tiene por objeto establecer unos límites más precisos de lo que a nuestro juicio debe entenderse por responsabilidad social, así como buscar una formulación más precisa de los instrumentos que permitirán adecuarla a los requerimientos de la sociedad presente, una sociedad aquejada de una gravísima afección económica; es decir, un modo más efectivo de enfrentar la tremenda crisis económica que estamos padeciendo, crisis que a juicio de políticos y economistas tiene su origen en una desconfianza absoluta hacia el sistema capitalista tal y como se nos ofrece en la actualidad.

Si bien el concepto de responsabilidad social, en el sentido en que se ha utilizado hasta hoy, es plenamente válido, sin embargo, adolece de una gravísima carencia inicial y es el hecho de su voluntariedad, o dicho con otras palabras, el dejarlo al arbitrio de sus propios actores y únicamente castigado su incumplimiento con una difusa sanción social. No se nos oculta que la causa de este nuevo planteamiento de la responsabilidad social ha tenido como detonante la increíble crisis económica o, mejor dicho, socioeconómica, en que nos hallamos inmersos.

En otras palabras, es la coyuntura económica, fruto de una crisis moral, social y política, la principal causa por la que se hace tan imprescindible y urgente una nueva concepción de responsabilidad social que sirva como herramienta eficiente para afrontar los actuales avatares que han puesto en jaque a las naciones más 
desarrolladas y ricas del planeta. Una nueva concepción de responsabilidad social no sólo exigible por la sociedad, sino por instancias más altas e incluso jurídicas que garanticen su cumplimiento.

Naturalmente, a todo el mundo se le alcanza la extraordinaria dificultad de poner en práctica las ideas mencionadas más arriba, lo que hace que para muchos tengan carácter utópico. Ello no significa que estas personas tengan razón en gran medida, puesto que a lo largo de los años los grandes avances sociales se han presentado como utopías inalcanzables; así, la jornada laboral de ocho horas, la prohibición del trabajo de los menores, el reconocimiento de los sindicatos como legítimos representantes de los colectivos de trabajadores e incluso, en otro orden de cosas, los derechos de las mujeres; nos resulta sorprendente a estas alturas que todavía en algunos países se les niegue incluso el acceso a la educación, manteniéndolas en un estado de incultura realmente atroz. Por ello, defendemos esta nueva concepción de la responsabilidad social corporativa, en la convicción absoluta de que antes o después será aceptada plenamente por la sociedad.

Además, a lo largo de estas páginas se pretende determinar la relación existente entre la denominada imagen pública de una institución o reputación y el modo de asunción de la responsabilidad social que manifiesta con su conducta dicha institución.

Es decir, partiendo de la concepción de que las Relaciones Públicas son una disciplina valorativa y finalista, en cuanto tienen por objeto la realización de un valor, la solidaridad social, a través de procesos de comunicación específicos, se establece la hipótesis subyacente siguiente: la solidaridad social, objetivo último de las Relaciones Públicas, está en función directa del grado de asunción de responsabilidad social que expresa una empresa, institución u organización con su conducta, que se resuelve en lo que se denomina imagen pública o reputación. En consecuencia, hay una relación causal entre tres factores: la concepción de la Relaciones Públicas de que partimos, la naturaleza y alcance de la llamada responsabilidad social y, por último, qué se entiende por imagen pública o reputación corporativa.

\section{Responsabilidad social corporativa}

Entendemos por responsabilidad social el conjunto de obligaciones inherentes a la libre asunción de un estado o condición, aún no reconocidas por el ordenamiento jurídico positivo o reconocidas sólo parcialmente, pero cuya fuerza vinculante y su previa tipificación proceden de la íntima convicción social de que su incumplimiento constituye una infracción de la norma de cultura (Solano Fleta, 1995).

Primero, la responsabilidad social se resuelve en un conjunto de obligaciones que se concretan en un dar, hacer o no hacer alguna cosa, de acuerdo con el clásico concepto ofrecido por el Derecho Romano, conec- 
tado con la asunción -por supuesto, libre y voluntaria- de un estado o condición socialmente trascendente y que por ello determina un comportamiento normado; segundo, ese conjunto de obligaciones constitutivo de un comportamiento aún no ha sido refrendado por el ordenamiento jurídico positivo, por lo que no es exigible; tercero, ese conjunto de obligaciones tiene fuerza vinculante e incluso, sanción, dado que tiene a un sujeto como punto final de imputación y una norma como referencia; en el supuesto de infracción, la sociedad pone en marcha su complejo mecanismo sancionador, cuyo espectro de posibilidades es inmenso; cuarto, esa fuerza vinculante halla su fundamento legitimador en el grupo social y en la valoración que el mismo realiza de los intereses en presencia, de acuerdo con la "norma de cultura".

El mundo empresarial, el "mundo de los negocios", en el decir angloamericano, sostenía y me atrevo a afirmar que sostiene en la actualidad, la responsabilidad social de la empresa, es decir, una responsabilidad que trasciende los angostos límites de la contenida en los textos legales que regulan la actividad industrial y mercantil y demás normas complementarias y que abarcan multitud de aspectos. Los economistas, al menos un sector suficientemente significativo de ellos, limitan esa responsabilidad al campo económico, afirmando que la responsabilidad de la empresa consiste, ni más ni menos, en la obtención del máximo beneficio, sin que se le pueda atribuir ninguna otra obligación, excepción hecha, claro está, de las de carácter fiscal, laboral, etc., a las que habría que añadir las que la presión social de la hora presente va cargando sobre sus "espaldas" (respeto del medio ambiente, lucha contra la contaminación, etc.).

No obstante y aunque aparentemente ambas posturas divergen radicalmente, la realidad no es así, ya que sus fronteras distan mucho de ofrecer perfiles nítidos y claramente diferenciados, supuesto que sus fundamentos se hallan en ámbitos dispares, obedientes las más de las veces a concepciones políticas, sociales y religiosas inspiradoras de unas filosofías vitales de carácter emocional o intuitivo y desde luego, de muy difícil racionalización, siquiera se nos presenten o pretendan presentar rodeadas de un halo de "cientificismo".

La razón de esa discordancia entre apariencia y realidad se halla en el hecho de que la idea e incluso el concepto de responsabilidad social se han ceñido exclusivamente o casi exclusivamente al "mundo de los negocios", esto es, al ámbito empresarial, más concretamente a la empresa, olvidando la existencia de otros campos cuya importancia no precisa ser subrayada. De ahí que nosotros pretendamos desvincularla de esas limitaciones y referirnos a los entes colectivos formales, expresión preferible a nuestro juicio a la generalmente utilizada, traductora de un pragmatismo muy difícil de conjugar con la visión generalista y universal del fenómeno.

A fin de cuentas y no obstante su importancia o trascendencia, la empresa constituye tan sólo una mera anécdota en el acontecer humano, un simple modo de producción, organización y distribución de bienes 
y servicios, surgido históricamente. De ahí que propongamos hablar de entes colectivos formales, expresión susceptible de abarcar tanto las empresas, o entidades con ánimo de lucro, como todas aquellas organizaciones sin ánimo de lucro, pero que, no obstante, se ven obligadas a rendir socialmente cuentas de su actividad, ya que en cualquier caso manejan unos recursos humanos y materiales escasos.

En cualquier caso y como inevitable concesión al uso de los tiempos, nos vemos obligados, como observará el lector, a referirnos constantemente a la empresa y no como sería nuestro gusto a los entes colectivos formales, expresión ésta más genérica y en consecuencia, más adecuada.

Sin duda, se trata de un tema polémico, siquiera ya esté admitido por gran parte de la doctrina y no sólo naturalmente en nuestro campo, sino en el mucho más espinoso de la ciencia económica, en la que se ha abierto paso paulatinamente. En gran medida, resulta sorprendente que fuera el mundo del Derecho el primero que dio el gran paso y en una institución que, desde Roma, se había considerado perfectamente cristalizada: el derecho de propiedad. Para el romano, en efecto, la propiedad era el "ius utendi, fruendi et abutendi”, es decir, el derecho de usar, disfrutar e incluso abusar de las cosas. En palabras infinitamente más elegantes y sin perder un ápice de rigor, nuestros grandes romanistas lo definían diciendo que era "el señorío jurídico sobre las cosas" (Iglesias Santos, 1957). Sin embargo, el derecho de propiedad, incluso en tiempos muy primitivos, estuvo sujeto a diversas limitaciones que, con el paso de los tiempos, fueron perfilándolo hasta convertirlo en una sombra de lo que antaño fue. La propiedad se concibe actualmente como un derecho social, por encima del cual se hallan los intereses de la sociedad, que priman siempre y en todo caso sobre él. Autores ha habido que niegan su existencia, considerándolo una enfiteusis. Sea como fuere, es lo cierto que la concepción del derecho de propiedad influyó sobremanera en la idea de la responsabilidad social que estudiamos. La empresa y haciendo abstracción de otros factores no desdeñables como, verbigracia, su consideración de ente artificial, cuya única justificación se halla en su consideración de servir del modo más idóneo para el fin para el que fue creada, no es ni puede ser nunca un ente absoluto ni en su constitución ni en su desenvolvimiento. La empresa está al servicio de la sociedad porque maneja recursos humanos y materiales naturalmente escasos, recursos que detrae del cuerpo social y que al dedicarlos a la producción de bienes o servicios determinados significa también que impide su aplicación a otros menesteres. Una analogía casi caricaturesca nos lo demuestra.

La responsabilidad social corporativa no debe estimarse jamás como una opción voluntaria por parte de las corporaciones, sino como una obligación ineludible que, en el futuro, será jurídicamente exigible incluso ante los órganos jurisdiccionales. 
Cuando se habla de responsabilidad social corporativa, es como si se tratara de una manifestación actitudinal defensiva ante circunstancias intolerables: la defensa del entorno, el salario justo, la defensa de los intereses del usuario o consumidor, etc. Ello es correcto y no hay nada que añadir; sin embargo, nosotros entendemos que hay que dar un paso adelante y dejar de configurar la responsabilidad social desde puntos de vista reactivos, sino activos, lo cual se corresponde con la figura, todavía escasamente desarrollada, del ciudadano corporativo.

En efecto, la empresa, la corporación, si se quiere, ha experimentado un grado de crecimiento tal que ha superado todas las previsiones; ya no es concebible la empresa que limita sus actividades a un mercado local, regional o incluso, nacional; sus acciones han desbordado fronteras y no sólo en el ámbito económico, sino también en el político; su poder económico ha desestabilizado gobiernos y ha impuesto, en ocasiones, gobiernos dictatoriales, usurpando la voluntad y la capacidad de decisión de los pueblos. No hace falta recordar el caso de Chile, en el que la ITT “derribó” al legítimo gobierno de Allende, apoyando al general "golpista” Augusto Pinochet e imponiendo una dictadura presumiblemente acorde con sus intereses.

Este formidable poder alcanzado por las mal llamadas empresas multinacionales -más adecuadamente deberían denominarse "transnacionales", siquiera tengan como nadie ignora una nacionalidad perfectamente identificada e identificable, es decir, sean plenamente "nacionales"-, no sólo ha afectado al mundo político y económico, sino también y es posiblemente lo más grave, a la sociedad, siquiera sean los aspectos antes mentados los más sobresalientes por más visibles.

En efecto, los tentáculos de estos formidables "leviatanes" alcanzan incluso hasta los mismísimos fundamentos de la "norma de cultura", comenzando por los propios idiomas vernáculos y concluyendo por los valores que, durante siglos, han sustentado las ideas y creencias de los pueblos. Nada se ha opuesto a su avance; ningún obstáculo los ha detenido. Incluso factores tales como el vestido o la alimentación han sido modificados radicalmente. Claro que esta situación dista mucho de ser nueva; pero lo que sí es nuevo es el hecho de que culturalmente ha representado una involución.

¿En qué concluirá esta crisis política y social? No pretendemos ser agoreros, ni tampoco profetas ni del bien ni del mal, sino sencillamente reflexionar acerca de un fenómeno que algunos han advertido, pero que muy pocos han sentido.

Sin duda, a lo largo de la historia, casi constituye un axioma que las culturas superiores concluyen por devorar a las inferiores, con independencia de que aquéllas vayan acompañadas de la espada. Roma latinizó a los pueblos ibéricos y germánicos, pero fue "conquistada” por Grecia, hasta el punto de que pocos años 
después de la invasión y conquista de la Hélade, los romanos cultos hablaban perfectamente el dialecto ático, la lengua de Atenas; incluso el médico de Nerón era griego, Pedacio Dioscórides Anazarbeo, autor de un tratado sobre las plantas medicinales, y la "Stoa” prendía en el espíritu romano.

Pero, no obstante este enseñoramiento cultural de los pueblos que se lleva a cabo, antes o después, por los pueblos intelectualmente mejor dotados, no significa que, en cierta medida, no se vean "contaminados" de algún modo por los contactos inevitables que impone la convivencia cotidiana; se toman expresiones, pero también se prestan; así, verbigracia, nuestra lengua es hija del latín, pero en ella abundan asimismo numerosos términos germánicos y árabes; incluso las creencias religiosas se ven salpicadas por las antiguas creencias y mitos primitivos; la Iglesia Católica o mejor dicho, el Cristianismo, asimiló muchas ideas paganas hasta el punto de que en multitud de ritos se puede observar la presencia de un verdadero sincretismo.

Desde este punto de vista, consideramos importante subrayar que el reconocimiento presente de la responsabilidad social de la empresa y su "popularidad", dentro del marco de la Unión Europea, se remonta a 1993, fecha en la que el entonces Presidente de la Comisión de las Comunidades Europeas, Jacques Delors, hizo un llamamiento a las empresas europeas para que participaran en la lucha contra la exclusión social; más tarde, en marzo de 2000, el Consejo Europeo de Lisboa apeló en particular al sentido de responsabilidad social de las empresas en lo relativo a las prácticas correctas en materia de aprendizaje permanente, organización del trabajo, igualdad de oportunidades, inclusión social y desarrollo sostenible. Posteriormente, la reunión de Gotemburgo, en junio de 2001, reiteró el viejo llamamiento delorsiano, si bien bastante más ampliado.

\section{Hacia una nueva concepción de la responsabilidad social corporativa}

Ahora bien, hasta aquí el concepto tradicional, añejo, de la responsabilidad social corporativa o lo que se entiende por ello. Pero, ¿es suficiente en los momentos actuales esa concepción de la responsabilidad social corporativa? Depende naturalmente del carácter instrumental con que se conciba. Si concebimos la responsabilidad social como un hecho absolutamente voluntarista, en el sentido de que se deje al arbitrio del empresariado, no cabe duda de que se puede mantener tal y como hemos explicitado; sin embargo, si la queremos convertir en un instrumento útil en situaciones críticas, tal como las que se dan en la actualidad, es decir, no como un instrumento de juguete o, en el mejor de los casos, como un medio de publicitar a determinadas empresas, debemos rechazar esa concepción. 
De otra parte, la idea subyacente en la responsabilidad social corporativa tiene un calado más que suficiente para hacer de ella un instrumento de suma importancia para colaborar en la superación de la crisis que estamos sufriendo, crisis que no es en absoluto exclusivamente de índole económica, sino que amplía su territorio a factores de naturaleza ética, política, social e incluso filosófica, en tanto en cuanto afecta a la propia fundamentación de la sociedad humana. Porque no nos engañemos, detrás de las quiebras que contemplamos, del formidable paro que existe y no sólo en nuestra sociedad nacional, sino a nivel mundial, subyace la quiebra de una concepción de vida que hunde sus raíces en la propia existencia humana; nos referimos al deterioro brutal de los sistemas políticos, de las concepciones religiosas, vigentes hasta ahora en nuestro mundo, a la mal llamada crisis de valores que no es tal, sino que es muchísimo mayor y que afecta a los valores porque éstos son los pródomos de una afección muchísimo más grave. Contemplando esa tontería, porque no merece más que ese nombre, de anuncios en autobuses de servicio público y que a no tardar los veremos, sin duda, en otros soportes, se nos antoja que tal vez, acaso, el problema económico no esté advirtiendo, como signo diagnóstico, de una afección infinitamente más profunda.

¿Qué concepción de responsabilidad propugna este trabajo? Se habla en él de un nuevo concepto de responsabilidad social corporativa, cuando en honor a la verdad más que de un nuevo concepto se trata de una modificación del mismo, si bien de naturaleza esencial, por cuanto como ya se ha mencionado se elimina el carácter voluntarista con que se manifiesta incluso en iniciativas internacionales como el Libro Verde, el Pacto Mundial..., estableciendo su obligatoriedad, si bien ello no significa que se articule como una norma jurídica por cuanto de ser así no hablaríamos de responsabilidad social, sino de responsabilidad jurídica.

De acuerdo con lo dicho, entendemos por responsabilidad social, desde esta nueva concepción, el conjunto de obligaciones amparado coercitivamente, tipificado en instrumentos "ad hoc" y cuyo incumplimiento sería sancionado no sólo socialmente, sino también jurídicamente.

Como se ha visto, se abandona el carácter voluntarista de su asunción, sin alterar las posibles repercusiones de carácter social, que podrían ampararse en el ámbito consuetudinario. Esta concepción se ampara en el Derecho consuetudinario, pero en el mismo sentido en que la Escuela Histórica alemana lo consideró como la única y verdadera fuente del Derecho.

No hay que olvidar que la asunción de una conciencia social no puede ser nunca una actitud de defensa frente a la sociedad, sino que debe responder a un convencimiento pleno de que la conducta que postula traduce un avance social, resultado de un cambio de la norma de cultura, de una modificación en la interpretación de los valores, basado en la conquista de unas perspectivas más amplias. Es decir, conforme avanza la sociedad, su perspectiva varía en función del horizonte o paisaje que va descubriéndose ante sus 
ojos y que origina, a su vez, una variación de los objetivos al presentarse un panorama absolutamente diferente del previsto. Igual sucede con la interpretación de los valores que lleva a cabo cada generación. Los valores son siempre los mismos, nada cambia, pero sí lo hace la perspectiva desde la que son contemplados por cada generación.

Sin embargo, el cambio de perspectiva no es algo gratuito ni caprichoso, sino que obedece al surgimiento de una específica sensibilidad, sensibilidad que implica un nuevo enfoque de las cosas y de la que, a fuer de sinceros, desconocemos sus causas; lo cierto es que primero de todo se manifiesta notablemente; más tarde, los científicos sociales, los eruditos los explicarán a entera satisfacción.

Así, la asunción plena de una conciencia social acorde con las exigencias de nuestro tiempo, o del tiempo que se trate, claro está, exige, en primer lugar, descubrir un rumbo de la evolución y a continuación, una vez tomado el pulso a la sociedad y explorados sus síntomas, formular su diagnóstico y su pronóstico, a fin, y continuamos con la analogía médica, de aplicar la terapia correspondiente.

El diagnóstico actual no es otro que una gravísima afección no sólo económica, sino social y política como ya se ha adelantado en estas páginas. En cuanto a la terapia, es evidente que es menester la adopción y aplicación de un conjunto de medidas que garantice la asunción de responsabilidad social propuesta por parte de los denominados entes colectivos formales. Aunque no faltan argumentos para mostrarse pesimistas o escépticos, no hay que olvidar que la responsabilidad social hace tiempo que se va abriendo camino en la conciencia universal y, lo que es más importante, se ha incorporado, con sus luces y sombras, a la norma de cultura de nuestro tiempo. Es cierto que todavía falta tiempo para que su rico contenido potencial se despliegue ante nuestros ojos, sin embargo lo importante es que vaya calando en la sociedad con la pretensión de que se instale cuanto antes para así enfrentarnos a dicha afección de la mejor y quizás única forma posible.

Los entes colectivos formales no podían hasta ahora eludir su responsabilidad social y ahora no sólo es que no puedan, sino que deben ampliarla a causa de unos muchos más amplios requerimientos sociales marcados por la crisis económica, social y política mundial. La responsabilidad social no es algo voluntario; tampoco es un instrumento más que se pone al servicio del empresario para la obtención de más y mejores beneficios; se trata de un conjunto de principios y obligaciones, la primera de las cuales es la de suministrar información exhaustivamente acerca de su comportamiento en todos los órdenes y la segunda liderar el progreso de la especie, es decir, llevar a cabo todo lo que posibilita el desarrollo social e individual, ya que el ciudadano corporativo ha desplazado al ser humano, considerado individualmente, en el papel protagónico en la sociedad. 
No se pretende convertir a los entes colectivos formales y, fundamentalmente, a las empresas en organizaciones no gubernamentales ni en partidos políticos u organizaciones religiosas, sencillamente se trata de exigirles el cumplimiento de las obligaciones que les impone la asunción del estado que voluntariamente han asumido y, por supuesto, la novísima situación o coyuntura económica, política y social que atraviesa la sociedad y que requiere unas actuaciones que a priori son extraordinarias, pero que deberán dejar de serlo e instalarse como ordinarias en el futuro.

Todo es posible, puesto que el hombre es el único ser capaz de modificar la historia. A diferencia del animal al que la vida le es dada completamente de antemano, sin que se le ofrezca la posibilidad de modificar un ápice su destino, el hombre, al que la vida se le ofrece como un quehacer, como tarea, es capaz de hacer su propia historia, como afirma José Ortega y Gasset. Pero entiéndase bien, se trata de una modificación estrictamente circunstancial, no sustantiva y esencial, y en ello y por ello, no tenemos más remedio que reconocer la razón que asistía a Skinner, campeón de un determinismo incomprendido pero, desde luego, absolutamente racional, mal que nos pese y mal que le pese a Chomsky.

\section{La imagen pública como consecuencia de la responsabilidad social corporativa}

Como hemos avanzado en líneas anteriores se pretende establecer la relación causal entre la idea de solidaridad y la responsabilidad social, de una parte; de otra, la relación asimismo causal entre asunción de responsabilidad social e imagen pública. Es decir, que la solidaridad es una consecuencia directa de la asunción de la responsabilidad; la imagen pública es, a su vez, consecuencia directa del grado de solidaridad manifestado.

Se trata de conectar sustantiva y formalmente la conducta social con los contenidos propios de la responsabilidad de esta naturaleza, que son todo menos caprichosos o arbitrarios y en consecuencia, se hallan íntimamente relacionados con la "norma de cultura" y con el llamado "carácter nacional", supuesto que tratamos de entidades históricas y, por ende, culturales.

En referencia a la imagen, todas las ideas subyacentes en el concepto concluyen a la postre por dirigirnos quiérase o no a la idea de responsabilidad social, de tal modo que puede afirmarse sin temor a errar que la "imagen" sigue a la responsabilidad social como la sombra al cuerpo. Ya se trate de un tipo de "imagen" u otro, todos están conectados en una relación de causa a efecto con la responsabilidad social, o séase, con las obligaciones inherentes a la asunción de la condición de "ciudadano corporativo" que la norma de cultura y fundamentalmente la lógica del devenir social ha atribuido a los entes colectivos formales, singularmente a las empresas económicas, verdaderos protagonistas del futuro del hombre.

$44 \mid n^{\circ} 9$ | doxa.comunicación 
La "imagen pública” o "reputación” social de los entes colectivos formales es consecuencia directa del cumplimiento o asunción de su responsabilidad social que manifiesta con su comportamiento o mejor dicho del grado de convicción social acerca de su cumplimiento; ello coincide con el fundamento de las propias Relaciones Públicas, es decir, el grado de aceptación social de una persona, empresa o institución está en función de su comportamiento de esta naturaleza, que no es otro sino el correspondiente al comportamiento esperado.

Las Relaciones Públicas tienen por objeto incrementar la cohesión social entre los individuos y entre los grupos, a través de la realización de un valor, la solidaridad, mediante procesos de comunicación específicos, y en ello reside precisamente su singularidad y su justificación ontológica. Por tanto, las Relaciones Públicas son una disciplina cultural, valorativa y finalista en tanto en cuanto persiguen la realización de dicho valor. Esta pretensión se realiza generalmente a través de procesos de comunicación grupales e intergrupales generadores de una reputación óptima, que es aquella que traduce en cada supuesto concreto los valores de la norma de cultura.

Por otra parte, el contenido de la "imagen pública" o reputación es la representación intelectual de la organización de que se trate de una serie de atributos representativos de valores, es decir, de atributos conectados con la "norma de cultura", norma que a su vez se halla relacionada, de una parte, con el "carácter nacional” y de otra, con el complejo actitudinal básico del sujeto observador, que al tener carácter colectivo coincide esencialmente con el "carácter nacional" mencionado. A lo largo de estas páginas hemos ido viendo la significación que los elementos endógenos o subjetivos y exógenos u objetivos tienen en la configuración de la "imagen" social, sea ésta de una persona individual o social, por lo que sobra toda reiteración al respecto.

En cualquier caso, conviene tener presente que sólo "grosso modo" cabe hablar de "imagen" de una persona individual o de una institución u organización, porque, en efecto, no hay una "imagen”, sino “imágenes” y éstas están en función de los diversos "públicos" de que se trate, y ello por lo que se refiere a sus factores subjetivos: intereses, necesidades y prejuicios (trinidad psicológica). Pero, aún hay más, una taxonomía general de la "imagen" nos ofrece el siguiente panorama: la "imagen” objetal, es decir, la "imagen” pura objetiva que proyecta el ente social de que se trate-una "imagen” meramente utópica, como la ecuación de los gases perfectos-. La "imagen" real es la "imagen” que proyecta en sus "públicos”, condicionada su percepción por factores tales como los intereses, necesidades, prejuicios, etc. Otra "imagen" que encontramos es la "imagen" adecuada, en el sentido de la "imagen" que debería corresponder a un determinado comportamiento y que está en función de su percepción social. Cabría asimismo, sin agotar, por supuesto, todas las posibi- 
lidades taxonómicas, hablar de la "imagen" deseada, tantas veces hija de una concepción errónea de la interpretación circunstancial de los valores y que determina lo que ha dado en llamarse muy gráficamente la "parada del reloj”. Nos estamos refiriendo a la concepción de la "imagen" como una entidad "poliédrica".

Sin embargo, la naturaleza poliédrica de la "imagen" no debe inducirnos al error de negar su entidad única; hay una pluralidad de "imágenes", pero sólo hay una "Imagen”; tal vez el recurso a una analogía religiosa nos permita comprender lo afirmado y desde luego, no pretendemos ser irreverentes, nada más lejos de nuestro ánimo. Hay una "imagen” como hay una sola Virgen María, siquiera existan multitud de advocaciones. Si diéramos un paso más, comprobaríamos como en la teología cristiana se habla de un solo Dios, pero también de Tres Personas; la Trinidad es tal vez la analogía más adecuada para la explicación del fenómeno de referencia, haciendo abstracción, como en el supuesto de la Virgen María, de cualesquiera otros factores exógenos que puedan inducir a malentendidos.

\section{Conclusiones}

Evidentemente la nueva concepción de responsabilidad social exige articularla en una serie de instrumentos susceptibles de realizarla en la práctica; sin más pretensión que mencionarlos por vía de ejemplos podríamos hablar de memorias sociales, rendiciones sociales de cuentas fiscalizadas por órganos del Estado. Sin duda, sorprenderá al lector que al final nos remitamos al Estado y a las normas del Derecho positivo, pero ello obedece a esa invasión que ha llevado a cabo en todos los ámbitos de la vida social, invasión que ha dejado en perpetuo estado de raquitismo, a cualesquiera otras manifestaciones de imposición sobre la conducta social. En cualquier caso, ello significa abandonar esa conexión formal o casi exclusivamente lógico-formal entre la imagen pública y el ejercicio de la responsabilidad social para llevarla a la realidad práctica y vital.

Al hablar de responsabilidad social corporativa, muchas personas pueden caer en la fácil tentación de considerar este tipo de responsabilidad como una especie de capricho o moda pasajera, hija de los tiempos que vivimos, exactamente igual que ocurre con la ecología. Estas concepciones obedecen a que en multitud de ocasiones han sido organizaciones políticas las que han levantado la bandera de sus reivindicaciones, mezclando lo que son auténticos requerimientos de las circunstancias con abundantes dosis de oportunismo político, lo que ha desmerecido su "imagen pública”. Pero, sucede, en lo que respecta a la responsabilidad social corporativa, que esta responsabilidad se halla afincada en las más íntimas convicciones éticas y jurídicas de las sociedades humanas, convicciones que aún no han encontrado posibilidad alguna de expresión normativa, dada la estatificación sufrida por el Derecho, sobre todo a partir de la codificación. 
En cuanto manifestación del sentir de la comunidad, los principios que fundamentan la responsabilidad social son los mismos que informan el "carácter nacional” y que se plasman en el complejo actitudinal básico de la sociedad; esto es, "dibujan”, por así decirlo, el "perfil” arquetípico de las organizaciones y expresan cómo concibe la sociedad que deben ser las mismas; esto es, son todo menos caprichosas.

Por ello, toda organización que acomode su conducta a los requerimientos sociales, es decir, al comportamiento esperado, de acuerdo con la norma de cultura de dicha sociedad, disfrutará de una "imagen pública" o "reputación" buena, en el sentido de ser reconocida como valiosa.

La “imagen pública”, "imagen corporativa” o "reputación” de una organización es la expresión manifiesta de la aceptación social por cuanto traduce al caso concreto la convicción o sentir de la colectividad, esto es, la norma de cultura.

En definitiva, la actividad publirrelacionística, enderezada a la creación y mantenimiento de la cohesión social, a través de procesos de comunicación específicos que desarrollan el valor solidaridad, se manifiesta en lo que ha dado en llamarse "imagen corporativa", "imagen pública” o "reputación pública".

La "imagen corporativa”, "imagen pública” o "reputación pública” es la consecuencia de un comportamiento adecuado a la "norma de cultura" y, en tanto en cuanto dicho comportamiento "traduzca" exactamente los requerimientos sociales básicos, la organización será aceptada como un ciudadano corporativo, que es, en última instancia, lo que expresa la "imagen corporativa”, "imagen pública” o "reputación pública”.

Se entiende por comportamiento adecuado la asunción por parte de la organización de las obligaciones inherentes a la responsabilidad social que le corresponde.

El fundamento de la responsabilidad social corporativa se halla, como el de la ética y el Derecho, en la norma de cultura, que es la íntima convicción "irracional” de que algo es justo o no lo es, sin que pueda darse explicación "racional” que lo avale.

No existe una "norma de cultura" universal, sino que cada pueblo, cada país, tiene la suya, si bien se considera que la correspondiente al país o países culturalmente más avanzados es la que debe funcionar como referente, como sucede en el ámbito del Derecho y concretamente en el Derecho Internacional. Si bien durante muchos años funcionó como referente jurídico el mundo de Occidente y frente a las infracciones que se cometían contra su concepción del Derecho podía invocarse la llamada "cláusula de orden público internacional”, en la actualidad, a partir de la creación de la "Sociedad de Naciones" primero y de la ONU, más tarde, las cosas se han simplificado algo, a lo que, sin duda, ha contribuido de modo extraordinario el desarrollo de las comunicaciones y la uniformidad cultural que, guste o no, se va imponiendo. 
Desde mi punto de vista o perspectiva, resulta indudable que la labor publirrelacionística se ha visto extraordinariamente facilitada por la denunciada uniformidad, que se extiende incluso a los aspectos lingüísticos y que presumiblemente irá "in crescendo", al menos para los hombres de nuestra generación. Sin embargo, no todo son aleluyas. Incluso los universalistas más acérrimos levantan su voz contra lo que creen que supone un gravísimo atentado cultural, al agostar civilizaciones que, en definitiva, constituyen un patrimonio precioso de la humanidad. Es más, el internacionalista auténtico, el internacionalista de raza y de cultura, es el mayor enemigo de esta globalización lingüística y cultural que impone, pero no convence, y que se esconde tras la apariencia de un modo mejor de entendimiento entre los hombres.

Como expertos en comunicación, nuestra obligación es denunciar la falacia que encapsula extender fuera de los estrictos límites formales de los procesos de comunicación, elementos pertenecientes a culturas exógenas.

Pero, como expertos en Relaciones Públicas, nuestro deber es luchar por establecer una cohesión social basada en el respeto a las ideas y creencias ajenas y en el supuesto de que sean absolutamente opuestas a las nuestras procurar mediante el diálogo y la comprensión llegar a un entendimiento que permita la convivencia.

\section{Referencias bibliográficas}

Capriotti, Paul (1999): Planificación estratégica de la Imagen Corporativa, Barcelona: Ariel.

Costa, Joan (2001): Imagen Corporativa en el siglo XXI, Buenos Aires: La Crujía Ediciones.

Cuesta, Marta de la y Galindo, Angel (Coords.) (2005): Inversiones socialmente responsables. Salamanca: Universidad Pontificia de Salamanca.

Cuesta, Marta de la y Rodríguez Duplá, Leonardo (coords.) (2004): Responsabilidad Social Corporativa. Salamanca: Universidad Pontificia de Salamanca.

Erbschloe, Michael (2002): Socially Responsible IT Management, USA: Digital Press.

Ettinger, K. E. (1961): Investigación y Relaciones Públicas, México: Herrero Hermanos Sucs.

Fernández Escalante, F. (1968): Relaciones Públicas. Fundamentos científicos y aplicaciones prácticas, Buenos Aires: O.E.L..

Fernández, O. A. B. (1973): Manual de Relaciones Públicas y Humanas, Buenos Aires.

Flores Bao, F. (1981): Relaciones Públicas. Ciencia de la integración humana, Lima: Desa.

Fundación Empresa y Sociedad (2003): De la transparencia a la confianza. Madrid

G. Perdiguero, Tomás (2003): La responsabilidad social de las empresas en un mundo global. Barcelona: Anagrama. 
Guardia Masso, Ramón; Renard, Lluis (1999): Estrategia competitiva y responsabilidad ¿Cómo hacerlas compatibles? Barcelona: Oikos-Tau.

Instituto de Ciencias Sociales (1963): Sociología de las Relaciones Públicas, Barcelona.

Lesly, Ph. (1981): Nuevo Manual de Relaciones Públicas, Barcelona: Martínez Roca.

Lougovoy, C. y Linon, M. (1972): Relaciones Públicas, Barcelona: Hispano Europea.

Low Jonathan y Kalafut, Pam Cohen (2002): Invisible Advantage: How Intangibles Are Driving Business Performance. USA: Perseus Books Group.

Makower, Joel (1995): Beyond the Bottom Line Putting Social Responsibility to Work Your Bus \& World. New York: Touchstone Books.

Martínez, Juan Luis, Simón, Cristina y Agüero, Ana (2003): La acción social de la empresa. Madrid: Prentice Hall-Financial Times.

Nielander, W. A. (1980): Práctica de las Relaciones Públicas, Barcelona: Hispano Europea.

Noguero i Grau, A. (1985): Información y técnicas de Relaciones Públicas, Barcelona: ESRP-PPU

Ortega y Gasset, 1928-1929

Raymond, S. (1970): Perspectivas de las Relaciones Públicas, México: Diana.

Rizzuto, F. A. (1964): Relaciones Humanas y Relaciones Públicas, Buenos Aires: Estrada.

Robinson, E. J. (1966): Comunicación y Relaciones Públicas, Columbus: Chaarles E. Merril Books.

Rodarte, F. F. (1966): La Empresa y sus Relaciones Públicas, México: Limusa-Wiley

Roggero, G. A. (1970): Relaciones Públicas, Bilbao: Deusto.

S Lee Smith, P. (1970): Relaciones Públicas de la Empresa, Bilbao: Deusto.

Solano Fleta, L. (1995): Fundamentos de las Relaciones Públicas, Sintesis, Madrid.

Spengler, Oswaldo (1923): Der Untergang des Abendlandes. La Decadencia de Occidente (trad., 2005), Madrid: Taurus/Fundación Ortega y Gasset.

Tothm, Elisabeth, L. And Robert, L. Heath (1992): Rhetorical and Critical Approaches to Public Relations, Hillsdale: Lawrence Erlbaum Associates.

Ugeux, W. (1976): Las Relaciones Públicas. Una nueva función social, Barcelona: Seix y Barral.

Varela, F. J. (1977): Teoría y práctica de las Relaciones Públicas, Barcelona: Gedisa.

Verdier, H. (1963): Táctica de las Relaciones Públicas, Barcelona: Hispano Europeo. 
